Journal of Social Sciences (COES\&RJ-JSS)

ISSN (E): 2305-9249 ISSN (P): 2305-9494

Publisher: Centre of Excellence for Scientific \& Research Journalism, COES\&RJ LLC

Online Publication Date: $1^{\text {st }}$ April 2017

Online Issue: Volume 6, Number 2, April 2017

http://centreofexcellence.net/J/JSS/JSS\%20Mainpage.htm

\title{
Health services in governmental hospitals in the capital governorate \\ (Evaluation study)
}

Ahmad Suliman Alhunaiti

Ministry of Public Sector Development, Amman, Jordan

\begin{abstract}
:
The study aimed to assess the health services in the governmental hospitals in the capital of Jordan, and recognize the reality of health services and the most important weaknesses related to limited medical staff, limited nursing staff, lack of medical supplies, lack of modern medical devices, the length of patients waiting periods, the treated patients and clients manner from the perspective of patients. This study relied on analytical descriptive approach through questionnaire distributed on 682 patients. The study found that there are several weaknesses in health care services at hospitals. The most significant weakness was the limited of medical and nursing staff. The numbers of doctors and nurses do not fit with the number of patients at hospitals, and the hospitals do not have alternative specialist in case of the absence of a doctor in a particular specialty. The study also pointed to inadequate of medical supplies permanently, and there is a lack in the presence of modern and advanced medical devices that forcing to transfer some patients to other hospitals, and the results also indicated that patients waiting periods was one of the biggest problems, which may expose patients to risk.
\end{abstract}

Keywords:

Governmental Hospitals, Medical Care, Medical Staff, Quality of Health Services. Citation:

Alhunaiti, Ahmad Suliman (2017); Health services in governmental hospitals in the capital governorate; Journal of Social Sciences (COES\&RJ-JSS), Vol.6, No.2, pp: 327347.

This work is licensed under a Creative Commons Attribution 4.0 International License. 


\section{الخدمات الصحية في المستثفيات الحكومية في محافظة العاصمة \\ احمد سليمان الحنيطي، وزارة تطوير القطاع العام ، عمان، الاردن}

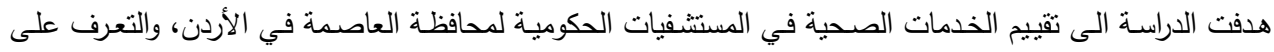
واقع الخدمات الصحية وأهم نقاط الضعف فيهامن حيث (محدودية الكادر الطبي، محدودية الكادر التمريضي، عدم التمدية تـوفر المسـلزمات الطبيـة، عـدم تـوفر الأجهزة الطبيـة الحديثـة، طـول فتـرات انتظـار المرضـى، أسـلوب معاملـة المرضسوالمراجعين) من وجهة نظر المرضى والمراجعين.

اعتمدت الدراسـة على المنهج الوصفي التحليلي من خـلاد اسـتبانة تم تطبيقها على عينـة بلغتت (682) مريضـا ومراجعا، وتوصلت الدراسة الى نتائج أهمها وجود العديد من نقاط الضعف في المسنتفيات المدروسة أهمها محدودية

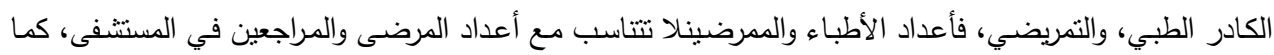
أنه لا يوجد لدى المستشفيات البديل المتخصص في حال غياب أحد الأطباء في تخصص اعداد معين.كما أثشارت الدراسة

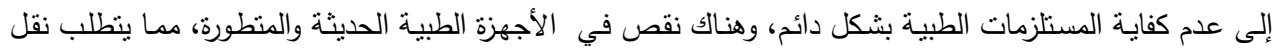
بعض الحالات الى مستثفيات أخرى،وقد أثنارت النتائج إلى أن فترات انتظـار المرضى هي الكي أكبر المشكلات التي يعاني منها مراجعو المستشفيات مما قد يشكل خطورة على المريض.

الكلمات الدالة: المسنتفيات الحكومية، الرعاية الطبية،الكادر الطبي، جودة الخدمات الصحية. 
Health Services in Governmental hospitals...

المقدمة

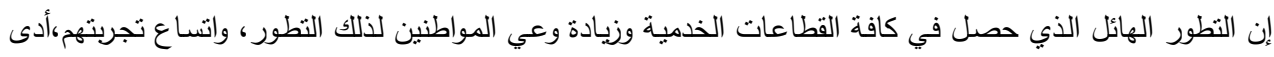

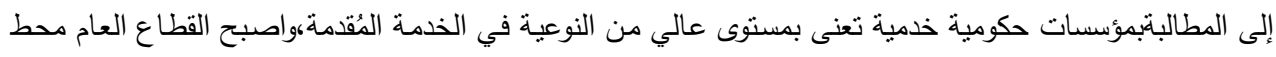

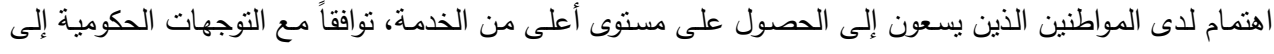

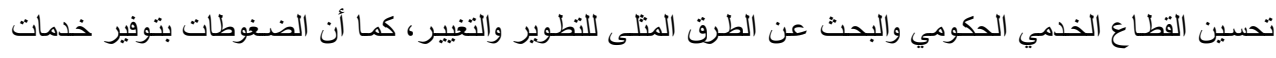

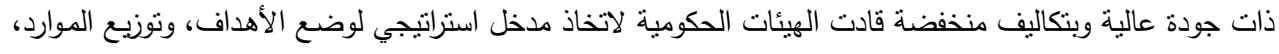

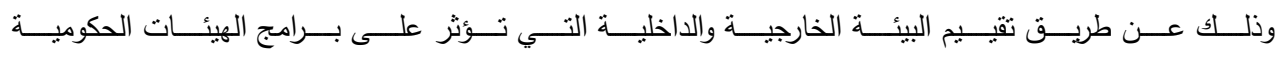

.(Bushnel\&Halus, 1992)

ولم تكن الأردنبمنأى عن ذلك التطور فقد عملت الحكومة على تحسين مستوى الخدمات المقدمة للمواطنين في كافة

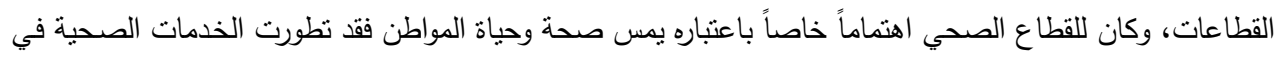

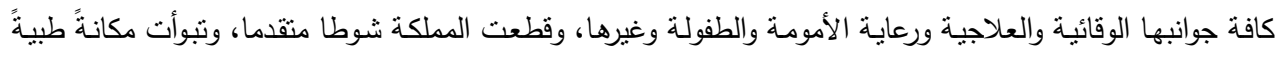

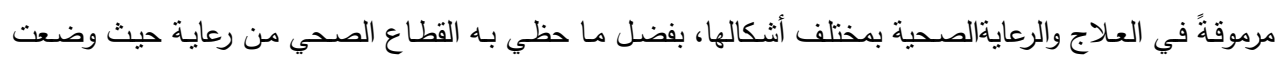

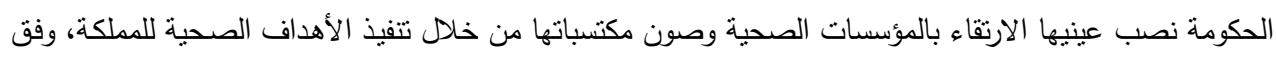

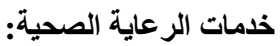

الخدمة بشكل عام تعني "أي فعلوأداء يمكن أن يقدمه طرف ما إلى طرف آخر يكون جوهره غير ملموس ولاينتج عنه أي تملك وإنتاجية " (Kotler,2006, p18).

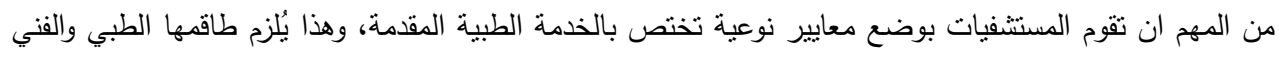

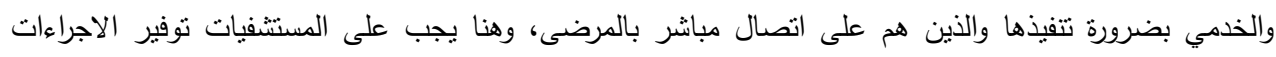

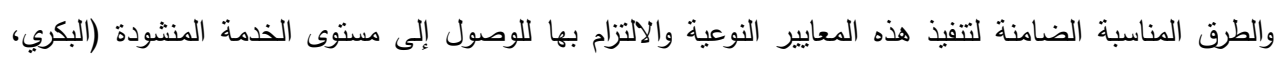

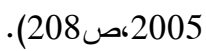

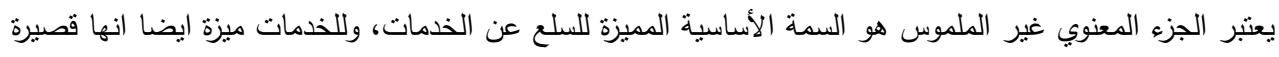

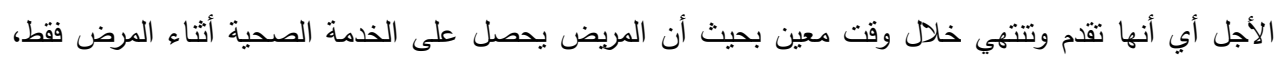

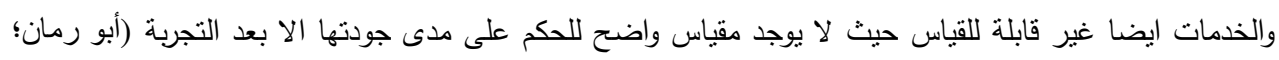

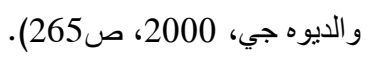

وجودة الخمات الطبية لها محوران: الاول محور انساني ويتمثل الاستجابة لطلبات المريض الانسانية كالعطف

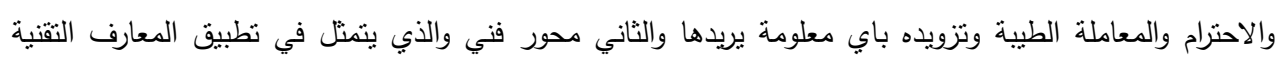

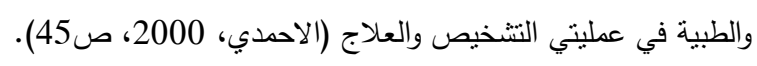

يمكن تعريف جودة الخدمة الطبية من جانب اجتماعي على أنها المسؤولية المناطة بالمنشأة الصحية كجهة لها ارتباط

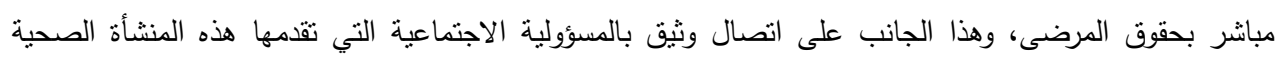


بغض النظر عن شكلها أو الههام التي تؤديها والذي يضمن لها انجاز ما تلتزم به نحو رعاية المرضى وضمان

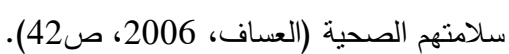
وكفاءة الخدمة الطبية من المنظور المهني الطبي تتمثل في تقديم أحسن الخدمات وأفضلها بما يتماشىى مع أحدث ما

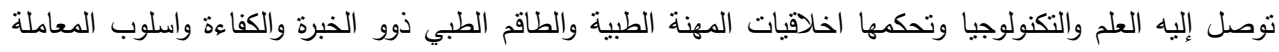
المثالي مع فئة المرضى وفئة الإداريين في المستشفى. Palmar, 1994,(p34).

وهناك صعوبة في تحديد مفهوم متفق عليه للجودة مما أدى إلى صعوبة في قياسها وهناك اختلاف في طريقة تقييمها

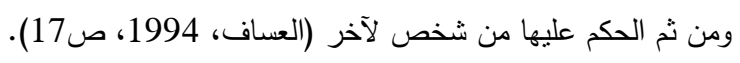

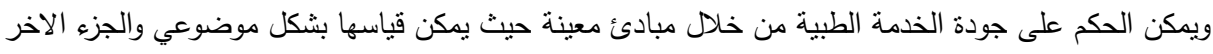

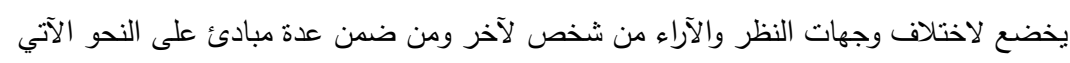
توحيد اجراءات وطرق ممارسة الخدمة الطبية.

الحد من الاخطاء الطبية المكن حدوثها.

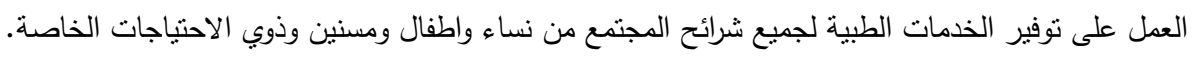

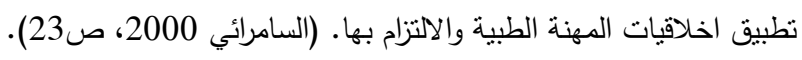

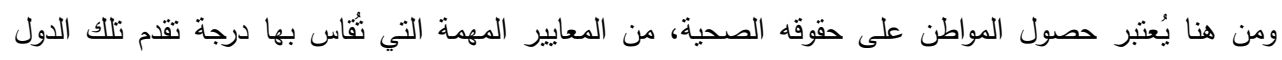

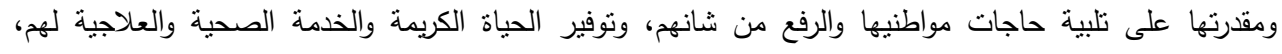

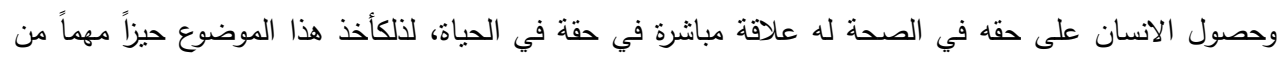

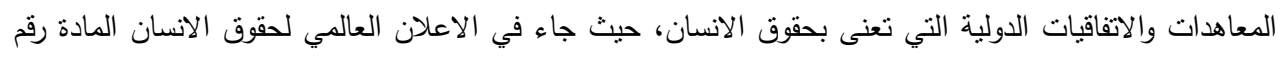

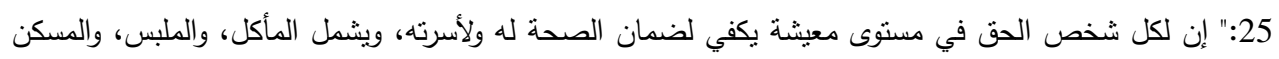

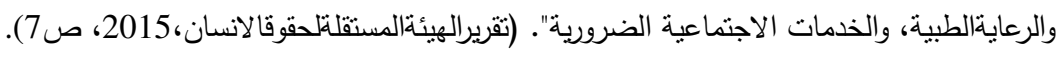

ولجودة الذدمات الطبية ثلاثة أبعاد أساسية يمكن النظر لها من خلال:

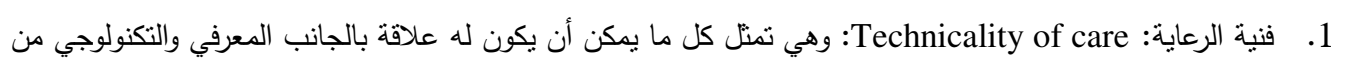

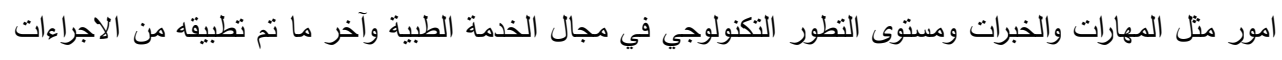
والاساليب المستخدمة في الرعاية الطبية. 2. فن الرعاية :Art of care: ويعني المعاملة السلوكية من قبل مقدمي خدمات الرعاية الطبية إلى منلقي هذه الخدمة

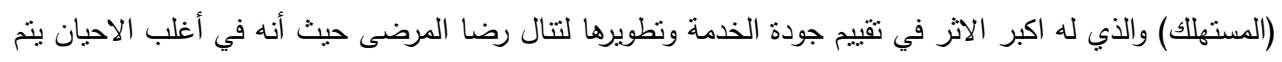
التركيز على الجانب التقني والتكنولوجي للارعاية العلاجية.

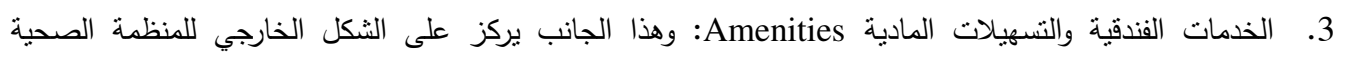

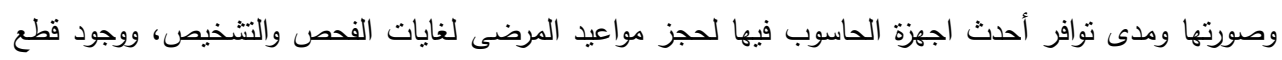

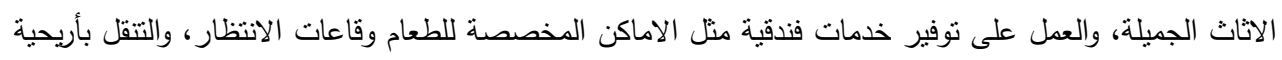

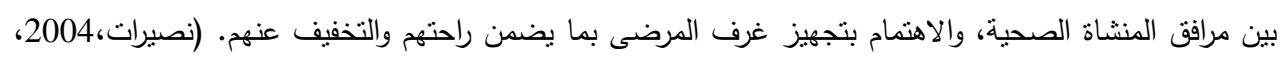
ص73) وتتححور الدراسة الحالية في تقييم الخدمات الصحية في الصستثفيات الحكومية في محافظة العاصمة. 
Health Services in Governmental hospitals...

مشكلة الاراسة

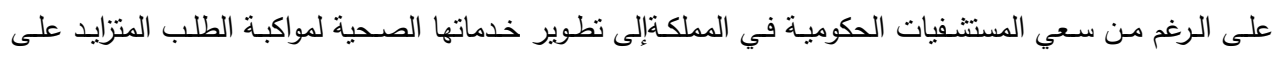

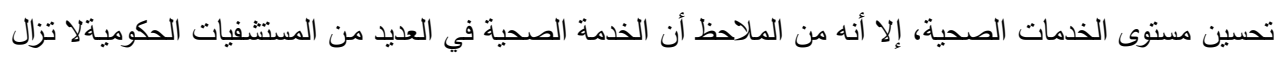

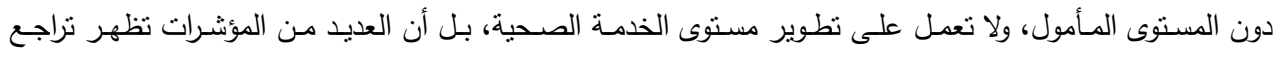

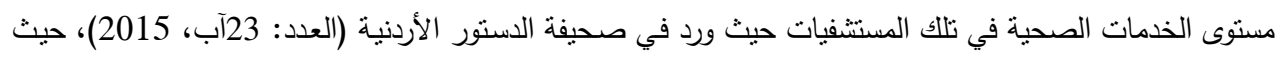
أوردت وجودنراجع في مستوى الخدمات بالمستثفيات والمراكز الصحية، كما ذكرت وجود شكاوى منعدد من المراجعين

حول تنني مستوى الخدمة الصحية.

كما أثنار الثواربة (2014) إلى وجود عدد كبير من الثكاوى من قبل المواطنين المستفيدين من خدمات الثأمين

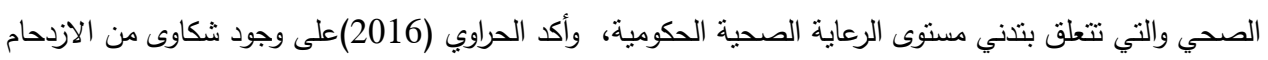
في عيادة "الباطني" في احدى المستشفيات الحكومية.

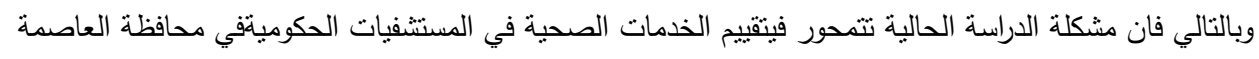

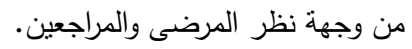

أسئلة الدراسة

تسعى الدراسة إلى الإجابة عن التنساؤلات النالية:

1

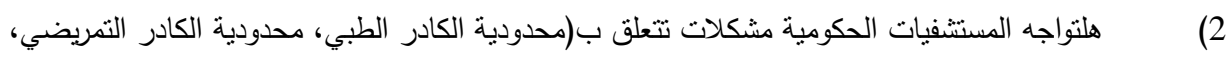

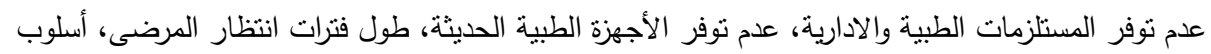

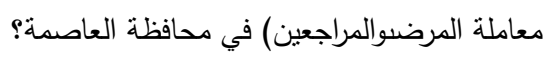

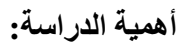

تعتبر الخدمة الصحية من أهم الخدمات التي تهم المواطن، وذلك نظراً لارتباطها بحياته وصحته، بالتالي فلدراسة

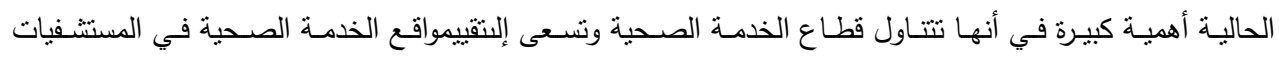

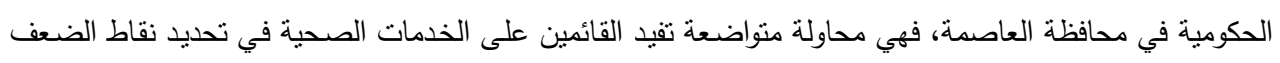

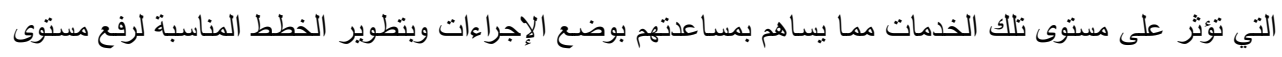
الخدمات الصحية الحكومية بما يتتاسب مع متطلبات وطموح المواطنين.

كما تكمن أهمية الدراسة الحالية في أنها من المواضيع التي تحظى باهتمامواسع من قبل الحكومات الأردنية والتني تسعى إلى تحسين الخدمة الصحية في الأردن بناءاً على التوجيهاتالملكية السامية.

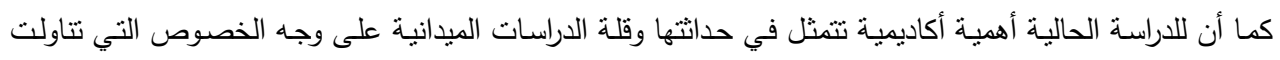

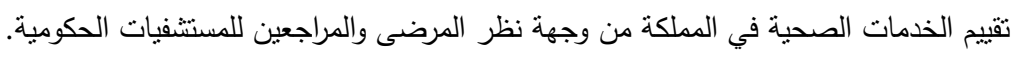

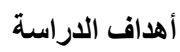

أن الهذف الرئيسي من الدراسة هو تقييم الخدمات الصحية في المستشفيات الحكومية في الأردن ولتحقيق ذلك الهدف

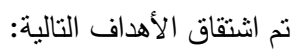


1) التعرف على واقع الخدات الصحية في المستثفيات الحكومية في محافظة العاصمة من وجهة نظر المرضى والمراجعين.

2) التعرف على أهم نقاط الضعف في واقع الخدمات الصحية المقدمة في المستشفيات الحكومية في محافظة العاصمة.

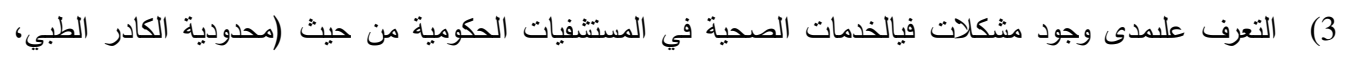

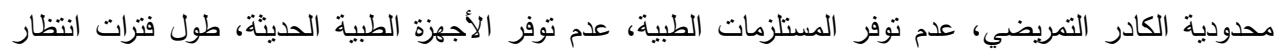

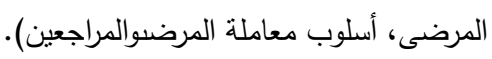

4) التوصل إلى نتائج وتوصيات من شانها أن نساهم في رفع مستوى الخدمة الصحية في المستثفيات الحكوميتبما بتوافق

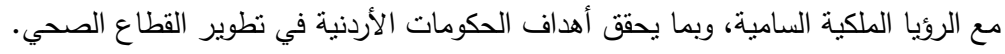
فرضيات الدراسة تقوم الدراسة على اختبار الفرضيات الثالية:

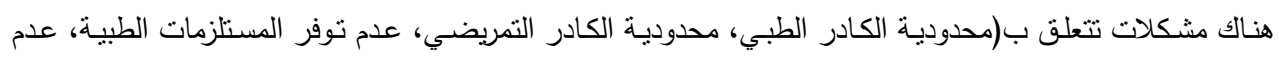

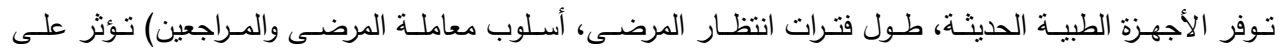
واقعالخدمات الصحية في المستشفيات الحكومية في محافظة العاصمة. هناك فروق ذات دلالة احصائية في آراء منلقي الخدمة الصحية حول واقع خدمات الرعاية الصحية في المستشفيات الصئية

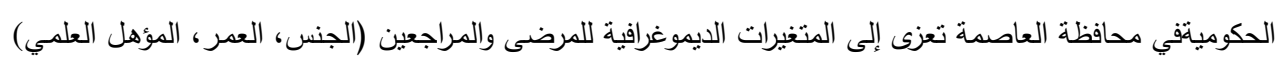

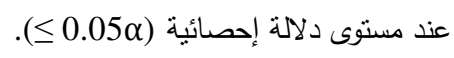

الإراسات السابقة هدفعبد القادر (2015) إلى قياس مستوى جودة الخدمات الصحية في المستثفيات الحكومية في السودان من وجهة

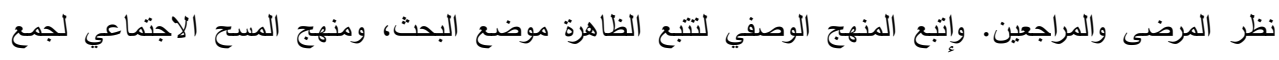

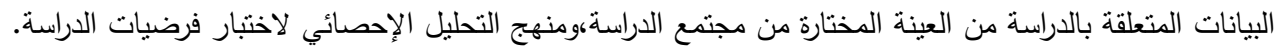

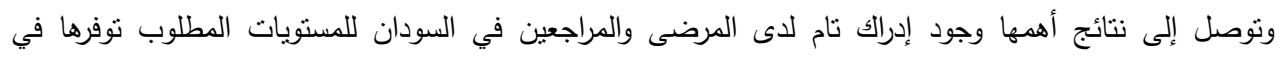

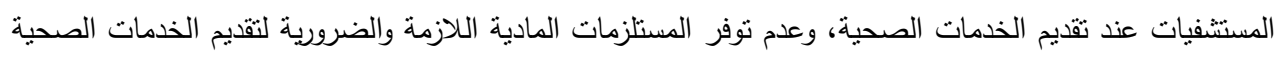

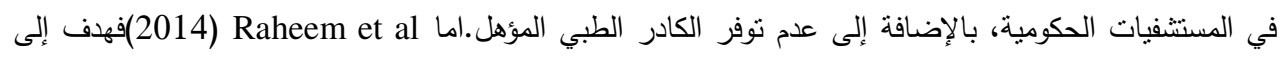

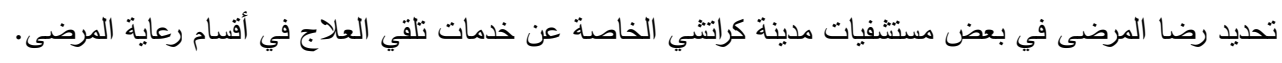

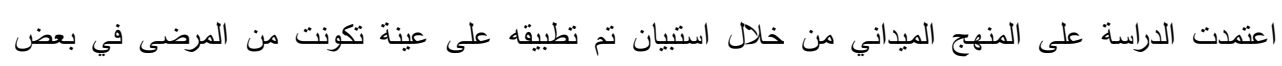

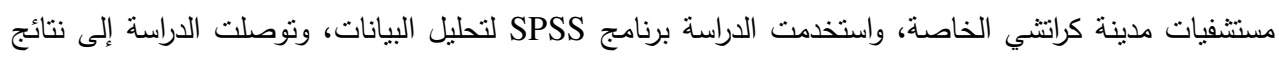

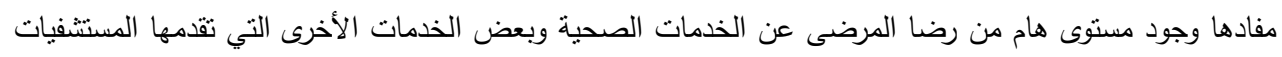
الخاصة في مدينة كرانتئ.

اما سلطان (2013)فهف إلمعرفة وتقييم مستوى الخذمات الصحية المقدمة إلى المستفيدين في المستشفيات الخاصة

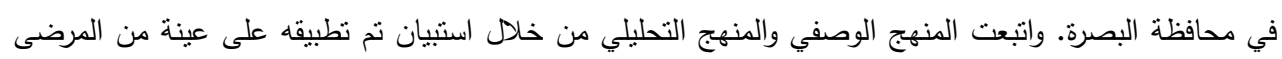

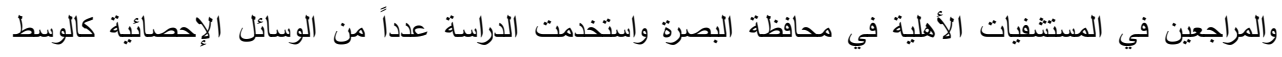


Health Services in Governmental hospitals...

الحسابي والانحراف المعياري ومعامل الارتباط البسيط وتحليل التباين ومستوى معامل الارتباط. وتوصلت الدراسة إلى

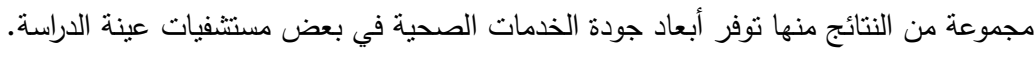

وهدف الضمور، وبوقجاني (2012) إلى معرفة أثر جودة الخذمات الصحية في درجة ولاء المرضى في مستشفى الإنى

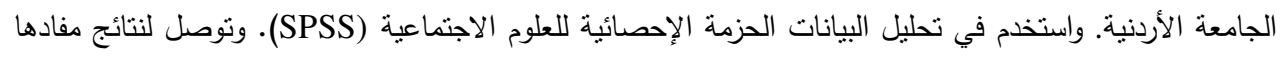

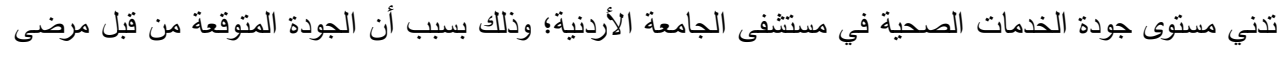

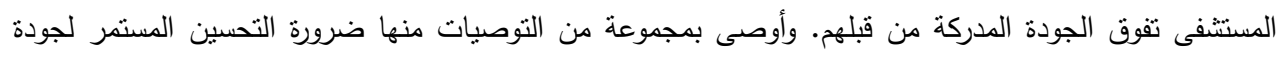

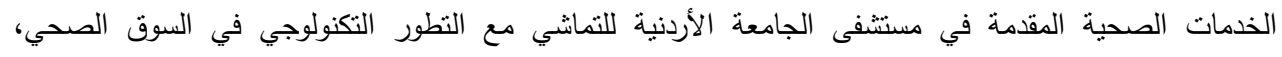

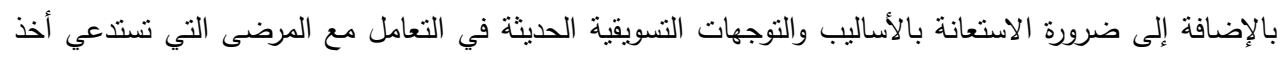

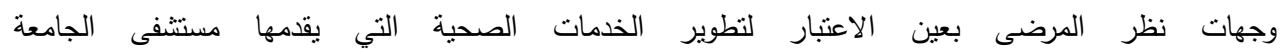

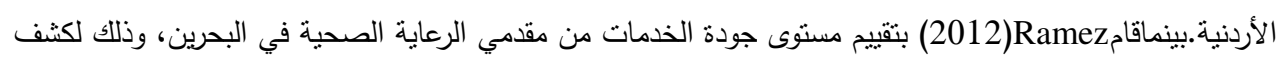

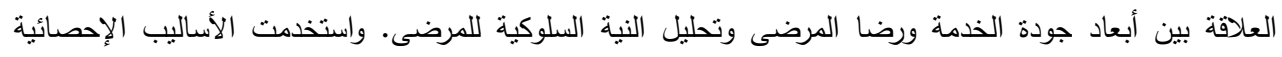

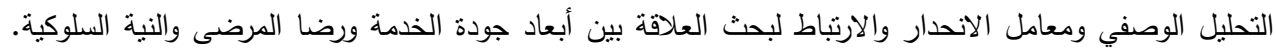

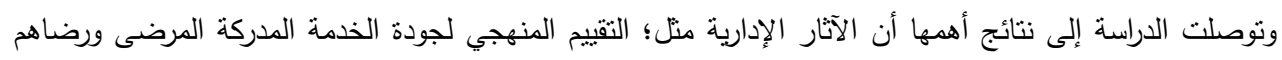
هو عنصر هام لتصميم استراتيجية التسويق لخدمات الرعاية الصحية.

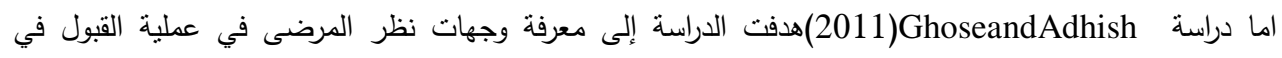

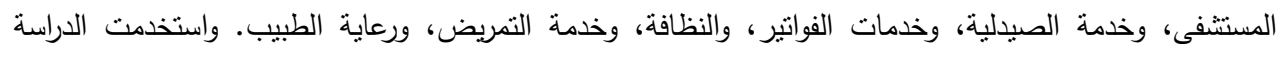

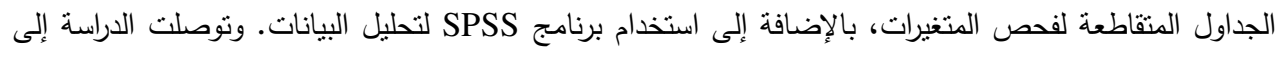

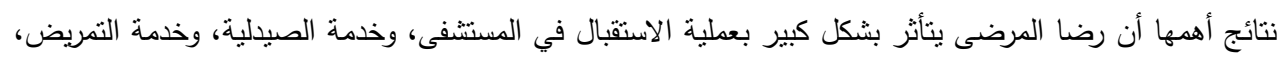

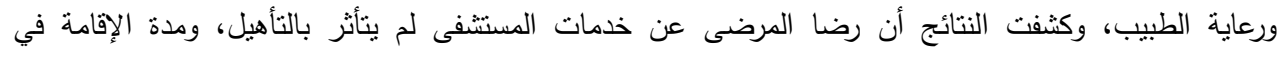
المستشفى والنظافة.

كما هدف الرواثدة والصمادي (2010) إلى تقييم مستوى الخدمات الصحية المقدمة للمستقفينين من القطاع الصحي

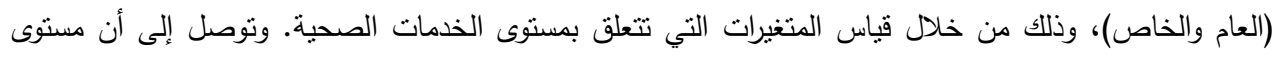

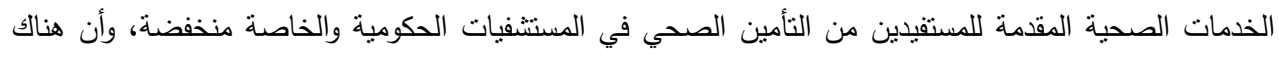

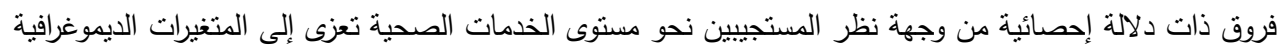

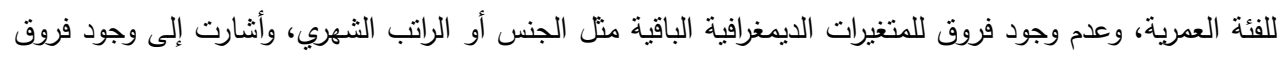

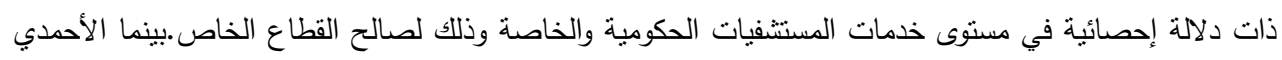
(2009)قيم أداء الخدمات الصحية في المملكة العربية السعودية من خلال قياس الكفاءة النسبية لمراكز الرعاية

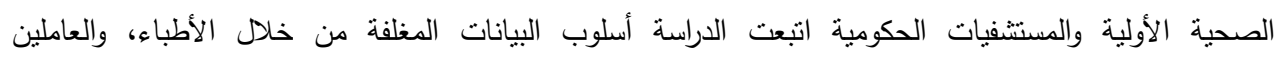

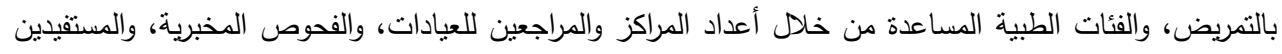

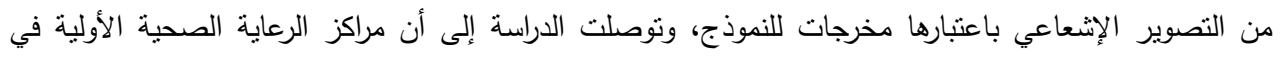

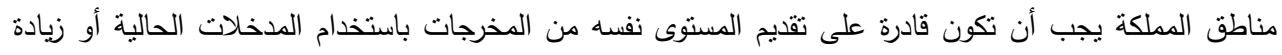

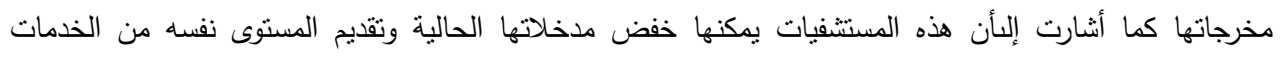


(المخرجات) أو زيادة خدماتها للمستفيدين باستخدام مستويات المدخلات الحالية نفسها، كما بينت الدراسة إلى أن عدد المناطق ذات الكفاءة الحكومية النسبية التامة من حيث كفاءة المستشفيات فيها (10) مناطق.

وقام مصلح (2009)بقياس مستوى جودة الخذمات الفعلية المدركة من قبل العاملين والمرضى في المستشفيات العاملة في مدينة قلقيلية. واعتمد المنهج الوصفي ومقياس SERVPERF لقياس جودة الخدمات المدركة والفعلية، وتوصلت إلى نتائج مفادها أن العاملين والمرضى راضين عن الخدات الفيات المقدمة لهم في المستشفيات العاملة في مدينة

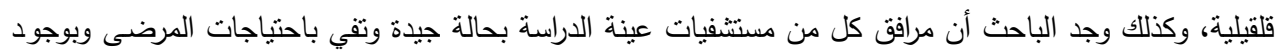

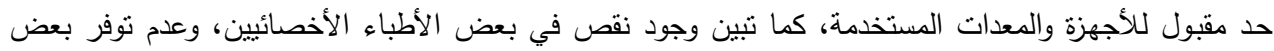

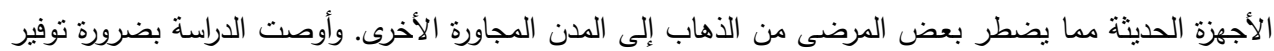
مستلزمات المستشفيات سواء كان ذلك من الأجهزة أو المعدات الحديثة، وتوفير دورات تدريبية ملائمة للعاملين كل في الكاتي مجاله من أجل تحسين جودة الخدمات الصحية المقدمة.

وهدف منصور (2006)إلى التعرف على الخدمات الصحية التي تقدمها المستثفيات للمرضى المنومين بمدينة أربد،

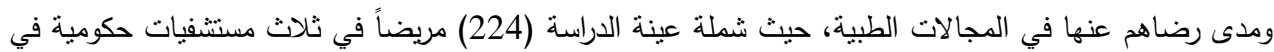
مدينة أربد. واستخدم استبانة خاصة لقياس رضى المرضى. وأظهرت نتائج الدراسة وجود مستوى منوسط من الرضا حول الخدمات الصحية المقدمة، كما وأظهرت أن الرضى عن مجال كادر التمريض أحتل المرتبة الأولى ومن ثم

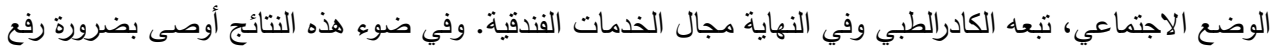

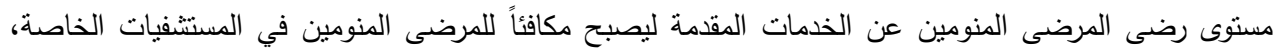
أضافه إلى الاهتمام بالكادر الطبي والتمريضي بالمريض بشكل أفضل وتوفير العدد الكافي وتوفير وسائل الراحة في في التئي

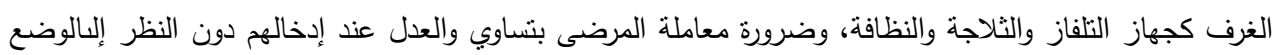
الاجتماعي للمريض أو الوساطة.

موقع الاراسة الحالية

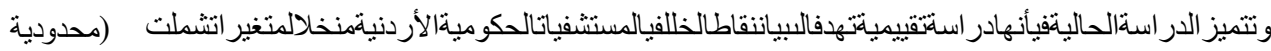
الكادر الطبي، محدودية الكادر التمريضي، عدم توفر المستلزمات الطبية، عدم توفر الأجهزة الطبية الحديثة، طول فترات انتظار المرضى، أسلوب معاملة المرضوالمراجعين)، وهيتمثلأ همؤُشر اتالخدمة فيالمستشفياتو التيتممنخلالها

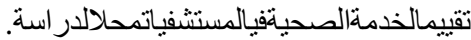

منهجية الاراسة تتبنى الدراسة منهج البحث الوصفي والذي يعتبر من أهم مناهج البحث العلمي حيث سيتم استخدامه نظراً لتوفر

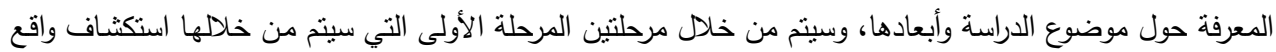

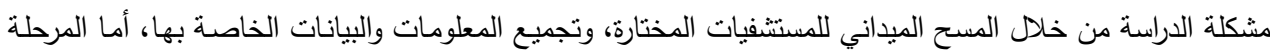
الثانية فسيتم من خلالها التتخيص والوصف المتعمق لواقع الخدمات الصحية في المستشفيات، وبما يسمح بالتوصل إلى معرفة دقيقة وتفصيلية عن عناصر موضوع الدراسة لتحقيق فهم أفضل لها ووضع سياسات وإجراءات وحلول تساهم في تحسين مستوى الخدمات الصحية في المستشفيات الحكومية في محافظة العاصمة. 
Health Services in Governmental hospitals...

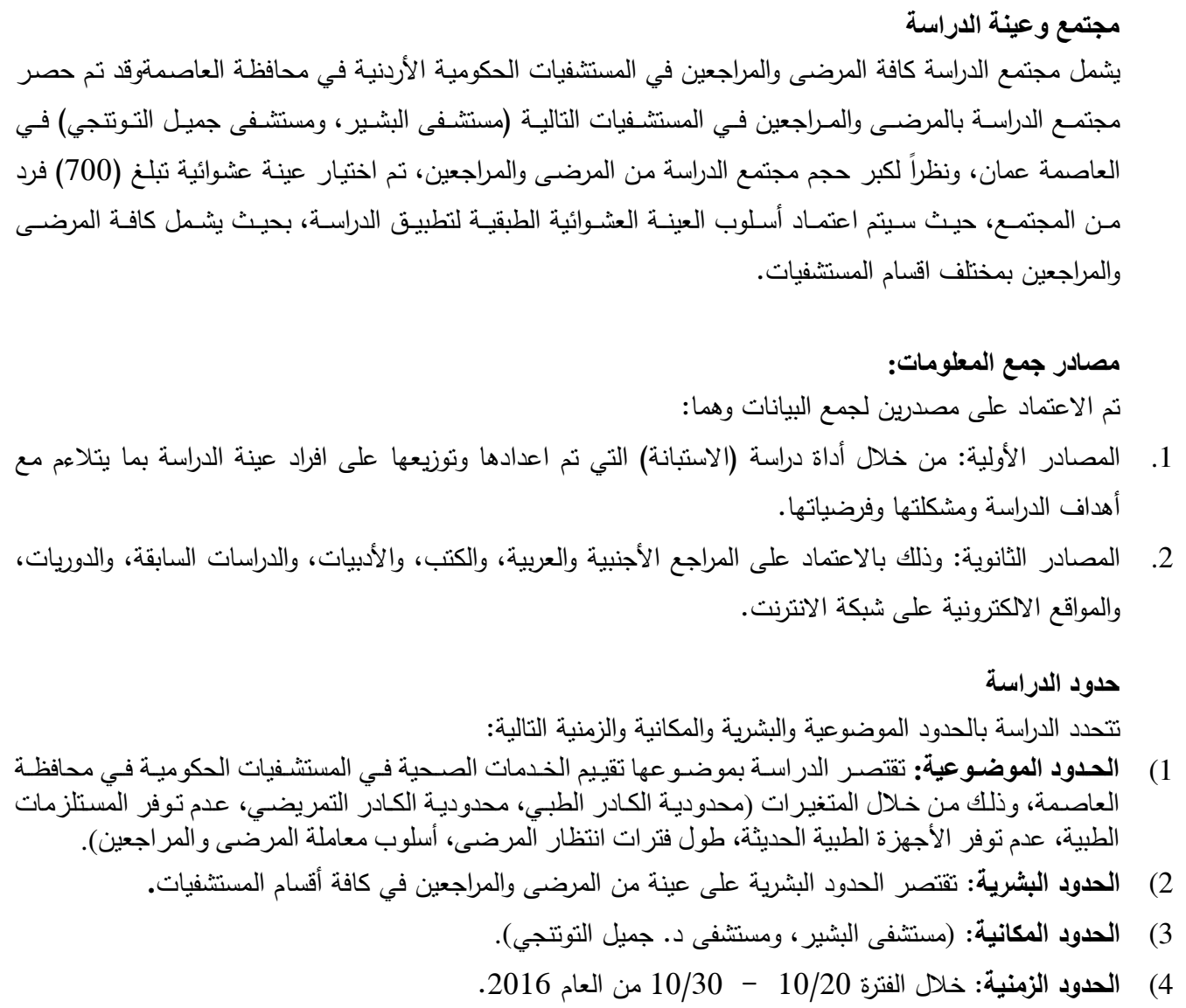


العينة على كل الأسئلة الموجودة في المقياس، كما يُمكن تفسير ألفا بأنها معامل الثبات الداخلي بين الإجابات، ويدل

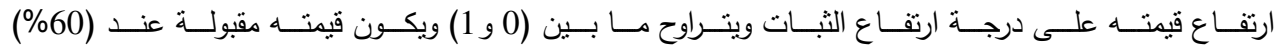
ومافوق(Cekaran,2003)،وقد بلغتقيمة (Cronbach's Alpha) (992.8\%) مما يشير إلى وجود اتساق داخلي بين فقرات كل مجال من الدالات، وبالتالي يدل هذا على أن فقرات الإستبانة كان بينها إنساق داخلي، مما يؤكد صلاحية ومدلولية الإستبانة في إختبار الفرضيات.

\section{الأساليب الإحصائية}

للإجابة على أسئلة الدراسة واختبار صحة فرضياتها سيتم استخدام الاختبارات الإحصائية التالية: مقياس الإحصاء الوصفي (Descriptive Statistics Measures): لوصف خصائص عينة

الدراسة، ولبيان درجة تقديرها لمتغيرات ومحاور الدراسة. اختبار التباين (ONE WAY ANOVA).

عرض النتائج واختبار الفرضيات هدفت الدراسة إلالتعرف على مستوى الخدمات الصحية في المستشفيات الحكومية في محافظة العاصمة، حيث تم توزيع 700 استبانة على افراد الدراسة وتم استرداد 682 استبانة وبعد التدقيق ثم استبعاد 11 استبانات لعدم اكتمال

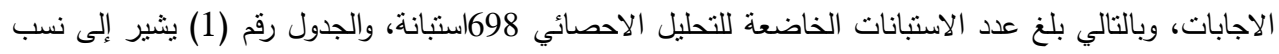

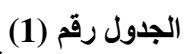

التوزيع:

ملخص حجم العينة

\begin{tabular}{|c|c|c|c|c|}
\hline المستردة اللى حجم & عدد الإستبانات & صداد الإستبانات غير للتحليل & غدد الإستبانات & حجم الاستبانات \\
\hline$\% 97.4$ & 682 & 11 & 7 & 700 \\
\hline
\end{tabular}

بعد تطبيق أداة الدراسة، جمعت استجابات أفراد عينة الدراسة، وحولت استجاباتهم إلى درجات ، ثم وجدت التكرارات والنسب المئوية، كما استخدم اختبار الاتساق الداخلي كرونباخ ألفا والمتوسطات الحسابية والانحرافات المعيارية واختبار الانحدار لبيانمستوى خدمات الصحية في المستشفيات الحكومية في محافظة العاصمة،وذللك عند مستوى الكياح الدلالة الإحصائية (2 (0.05). لتحليل بيانات وإختبار فرضيات الدراسة نم الاعتماد على مقياس ليكرت الخماسي في الإجابة علالأسئلة وذلك حسب الدرجة التالية: درجـة (1) تعبر عن: غير موافق بشـدة. درجـة (2) تعبر عن: غيـر موافق. درجـة (3) تعبـر عن: موافق بدرجـة

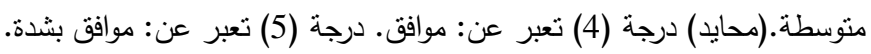

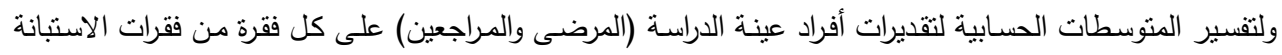
وعلى كل مجال من مجالاتها؛ نم استخدام المعيار الإحصائي الآتي والمبين في الجدول (2): 
Health Services in Governmental hospitals...

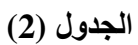

المعيار الاحصائي لتفسير المتوسطات الحسابية لتقديرات افراد عينة الدراسة (المرضى والمر اجعين) على كل فقرة

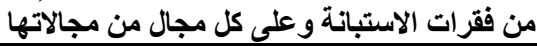

\begin{tabular}{|c|c|}
\hline درجة الموافقة & المتوسط الحسابي \\
\hline بدرجة متدنية & من 1.00 - أقل من 2.49 \\
\hline بدرجة منوسطة & من 2.50 - اقل من 3.49 \\
\hline بدرجة عالية & من 3.50 - 5.00 \\
\hline
\end{tabular}

وصف خصائص عينة الاراسة:

1

تتاولت الدراسة جملة من المتغيرات الديموغرافية لأفراد عينة الدراسة من حيث "الجنس،العمر المؤهل

التعليمي "، والمستقاة من المعلومات العامة التي تضمنتها الاستبانة، واستتادا على ذلك تم وصف عينة على الدراسة

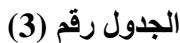

وصف عينة الدراسة وفق المتغيرات الديموغرافية لأفراد الدراسة

\begin{tabular}{|c|c|c|c|}
\hline النسبة المئوية\%\% & 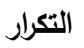 & المستوى/(الفئة & 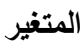 \\
\hline 76.7 & 523 & ذكر & \multirow{3}{*}{ 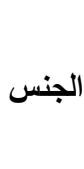 } \\
\hline 23.3 & 159 & أنثى & \\
\hline$\% 100.0$ & 682 & المجموع & \\
\hline 21.3 & 145 & 20 سنة فاقل & \multirow{6}{*}{ 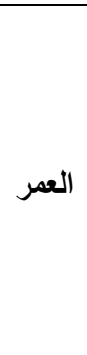 } \\
\hline 13.2 & 90 & 21- 21 سنة & \\
\hline 12.9 & 88 & 31- 30 سنة & \\
\hline 22.3 & 152 & 41- 40 سنة & \\
\hline 30.4 & 207 & 51 سنة فمافوق & \\
\hline$\% 100$ & 682 & المجموع & \\
\hline 62.9 & 429 & ثانوية عامة فما دون & \multirow{5}{*}{ العلمي } \\
\hline 7.6 & 52 & دبلو متوسط & \\
\hline 4.8 & 33 & بكالوريوس & \\
\hline 24.6 & 168 & دراسات عليا (ماجستير ، ودكتوراه) & \\
\hline$\% 100$ & 682 & المجموع & \\
\hline
\end{tabular}

نتائج التحليل

تحليل آراء عينة الدراسة للعبارات الخاصة بمستوى الخدمات الصحية في المستشفيات الحكومية في محافظة العاصمة بهدف التعرف على آراء أفراد عينة الدراسة حول مسنوى تلك الخدمة، حيث تم حساب المتوسطات الحسابية 
والانحرافات المعيارية لكل مجال.

مستوى الخدمة الطبية محدودية الكادر الطبي

المتوسطات الحسابية والانحرافات المعيارية للفقرات المتعلقة بمشكلة محدودية الكادر الطبي ويشير الجدول رقم (4) جدول (4)

إلى النتائج:

المتوسطات الحسابية والانحر افات المعيارية لاستجابات أفراد عينة الدراسة فيما يتعلق بفقرات محدودية الكادر الطبي أنجي

\begin{tabular}{|c|c|c|c|c|}
\hline درجة التقدير & الانحراف & المتوسط & الفقرة & رقم الفقرة \\
\hline 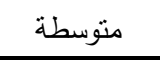 & 1.263 & 2.994 & نتتاسب أعداد الأطباء مع حجم المرضى في المستشفى. & 1 \\
\hline متوسطة & 0.848 & 3.069 & يتوافر في المستشفى عدد كاف من الأطباء ذوو التخصصات & 2 \\
\hline متوسطة & 0.796 & 3.176 & وحالات المرضى في المستشفى الأطباء الذين بيتاسب تخصصاتهم & 3 \\
\hline متوسطة & 1.140 & 2.710 & في لدى المسنشفى البديل المتخصص في حال غياب أحد الأطباء & 4 \\
\hline متوسطة & 1.012 & 2.987 & متوسط المحور & \\
\hline
\end{tabular}

* الارجة الانيا (1) واللارجة القصوى من (5)

يُلاحظ من الجدول (4) أن المتوسطات الحسابية لاستجابات أفراد عبنة الدراسة تراوحت مابين [2.710-

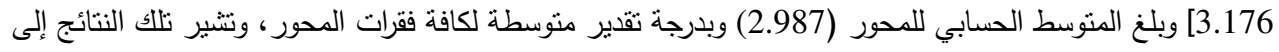
وجود نقص في الكادر الطبي في المستشفيات تمدراستها مقارنة بعدد المراجعين. محدودية الكادر التمريضي:

المنوسطات الحسابية والانحرافات المعيارية للفقرات المتعلقة بمحدودية الكادر التمريضي، ويشير الجدول رقم (5) إلى

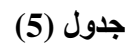

النتائج:

المتوسطات الحسابية والاتحر افات المعيارية لاستجابات أفراد عينة الدراسة فيما يتعلق بمحدودية الكادر التمريضي

\begin{tabular}{|c|c|c|c|c|}
\hline درجة التقدير & الانحراف & المتوبط & الفقزة & رقم الفقرة \\
\hline متوسطة & 1.210 & 3.073 & يتتاسب أعداد الكادر التمريضي مع حجم المرضى في & 5 \\
\hline متوسطة & 1.119 & 3.322 & يتتاسب عدد الممرضين مع عدد الاطباء. & 6 \\
\hline منوسطة & 1.117 & 2.940 & هناك توافر في اعداد الممرضين على مدار الساعة. & 7 \\
\hline
\end{tabular}


Health Services in Governmental hospitals...

\begin{tabular}{|l|l|l|c|c|}
\hline هناك عدد ممرضين كافٍ لإتمام أعمال التمريض المطلوبة. & 8 & 8 \\
\hline متوسطة المحور & 1.178 & 2.947 & $\mathbf{3 . 0 7 0}$ & \\
\hline
\end{tabular}

* الدرجة الانيا (1) والارجة القصوى من (5) الدان

يُلاحظ من الجدول (5) أن المنوسطات الحسابية لاستجابات أفراد عينة الدراسة نراوحت مابين[2.940-

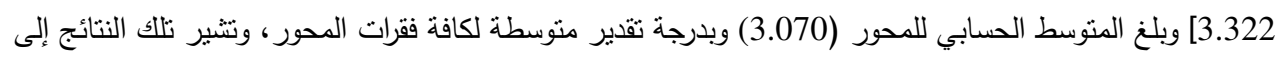

وجود مستوى متوسط في تتاسب الكادر التمريضي في المسنتفيات موضوع الدراسة، مما يثير الى محدودية الكادر التمريضي في المسنشفيات عبنة الدراسة، وعدم تتاسبه مع اعداد المرضى.

توفر المستلزمات الطبية:

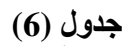

المتوسطات الحسابية والانحرافات المعيارية لاستجابات أفراد عينة الدراسة فيما يتعلق بتوفر المستلزمات الطبية

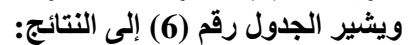

\begin{tabular}{|c|c|c|c|c|}
\hline درجة التقدير & الانحراف & الحسابي * المتوسط & الفقرة & رقم الفقرة \\
\hline متوسطة & 1.174 & 2.940 & نتوفر في المستشفى كافة الأدوية والمستلزمات الطبية بشكل & 9 \\
\hline منوسطة & 0.903 & 3.323 & تتوفر في المستشفى الأدوات الطبية الكافية للنشخيص. & 10 \\
\hline متوسطة & 0.993 & 3.353 & بشكل كافٍ في المستشفى الأدوات الطبية الكافية للعمليات الجراحية & 11 \\
\hline متوسطة & 1.175 & 3.087 & بتشكل دائم وكافٍ المستشفى المستلزمات الطبية المساندة للرعاية الصحية & 12 \\
\hline متوسطة & 1.385 & 2.803 & لائم يوجد نقص في أي مستلزمات طبية الواجب نوفرها بشكل & 13 \\
\hline متوسطة & 1.126 & 3.101 & متوسط المحور & \\
\hline
\end{tabular}

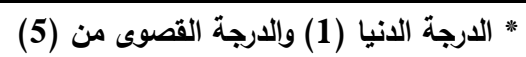

يُلاحظ من الجدول (6) أن المتوسطات الحسابية لاستجابات أفراد عينة الدراسة تراوحت مابين [2.803-

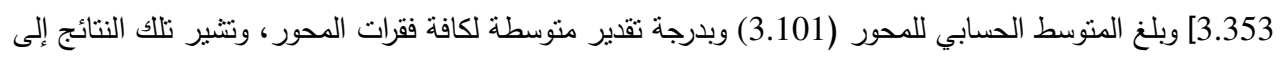

عدم توفر الاجهزة الطبية الحديثة بشكل مناسب ودائم في المستشفيات موضوع الدراسة. 
توفر الأجهزة الطبية الحديثة:

\section{جدول (7) (ل)}

المتوسطات الحسابية والانحرافات المعيارية لاستجابات أفراد عينة الدراسة فيما يتعلق بتوفر الأجهزة الطبية

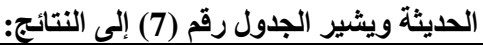

\begin{tabular}{|c|c|c|c|c|}
\hline درجة التقدير & الانحراف & الحسبابي * المتوسط & 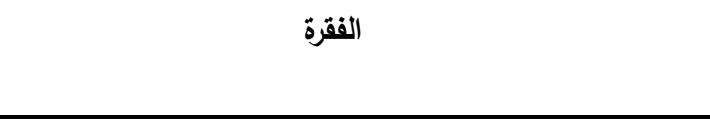 & رقم الفقرة \\
\hline متوسطة & 1.129 & 2.959 & يتوفر في المسنتفى الأجهزة الطبية المتطورة والحديثة. & 14 \\
\hline 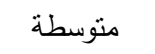 & 0.973 & 3.391 & يتوفر في المستشفى أدوات ومواد فنية جيدة لإجراء الفحوصات. & 15 \\
\hline متوسطة & 1.411 & 2.699 & ينوفر في المستشفى أنظمة اتصال فعالة بين الأقسام. & 16 \\
\hline متوسطة & 1.183 & 3.084 & يتوفر في المستشفى غرف عمليات ذات تجهيزات طبية منطورة. & 17 \\
\hline منوسطة & 1.224 & 3.224 & ينوافر أجهزة فحص وتحليل وأشعة فعالة ومتطورة. & 18 \\
\hline متوسطة & 1.184 & 3.071 & متوسط المحور & \\
\hline
\end{tabular}

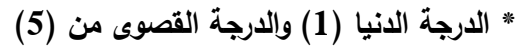

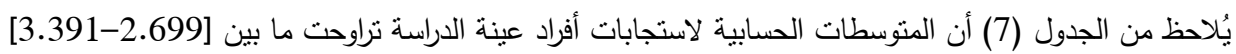

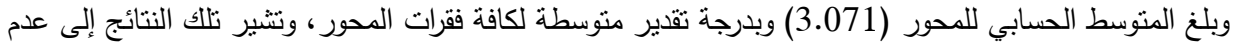
توفر المستلزمات الطيبة بدرجة كافية في المستثفيات المدروسة.

جدول (8)

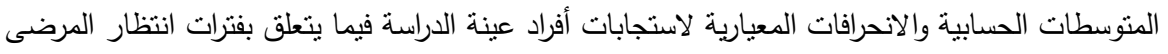
ويشير الجدول رقم (8) إلى النتائج:

\begin{tabular}{|c|c|c|c|c|}
\hline التقدير & الانحراف & المتوبط & الفقرة & رقم \\
\hline 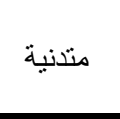 & 1.063 & 2.078 & فترات انتظار المرضى للحصول على الخدمة الصحية & 19 \\
\hline عالية & 1.075 & 3.608 & فترات الانتظار طويلة لعدم توفر الأخصائيين. & 20 \\
\hline عالية & 1.163 & 3.657 & فترات الانتظار طويلة لعدم توفر الغرف في المستشفى. & 21 \\
\hline منوسطة & 1.516 & 3.194 & لا يوجد تأخير في فترات الانتظار للحالات الطارئة. & 22 \\
\hline متوسطة & 1.387 & 2.729 & هنال إدارة فاعلة لفترات انتظار المرضى تساهم في توزيع الفريع الطبي & 23 \\
\hline
\end{tabular}

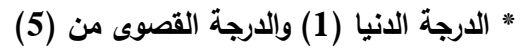

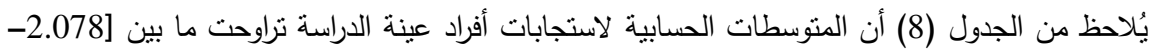

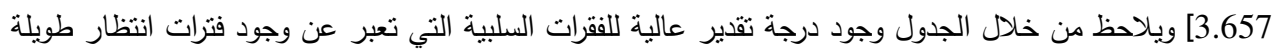


Health Services in Governmental hospitals...

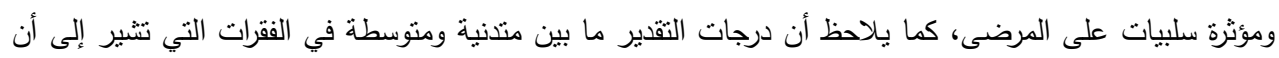

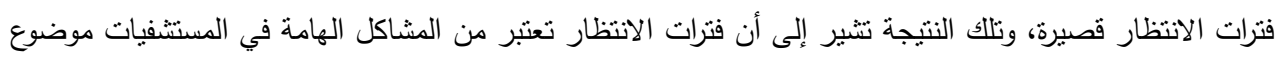
الدراسة.

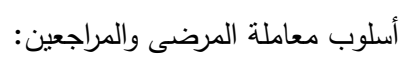

جدول (9)

المتوسطات الحسابية والانحرافات المعيارية لاستجابات أفراد عينة الدراسة فيما يتعلق بأسلوب معاملة

\begin{tabular}{|c|c|c|c|c|}
\hline التقدير & 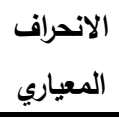 & الحسابيث* & 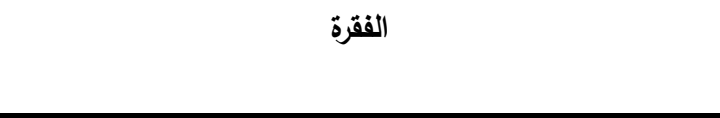 & رقة - مقرة \\
\hline 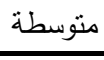 & 1.088 & 2.709 & يبدي العاملين في المستثفى الاستعداد التام للتعاون مع المرضى. & 24 \\
\hline عالية & 1.073 & 3.587 & وممرضيها. & 25 \\
\hline 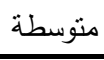 & 1.068 & 2.682 & يتسم سلوك العاملين في المستشفى بالأدب وحسن المعاملة. & 26 \\
\hline 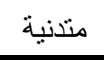 & 1.036 & 2.299 & يصني العاملون في المستشفى بشكل كامل إلى شكاوى المرضى. & 27 \\
\hline 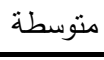 & 0.939 & 2.893 & يتحلى العاملون بالقيم المهنية بشكل كبير. & 28 \\
\hline 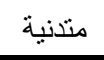 & 1.183 & 2.405 & يهتم العاملون بالمريض بغض النظر عن العلاقات النخصية. & 29 \\
\hline 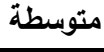 & 1.064 & 2.763 & متوسط المحور & \\
\hline
\end{tabular}

* الارجة الدنيا (1) والارجة القصوى من (5) الدان

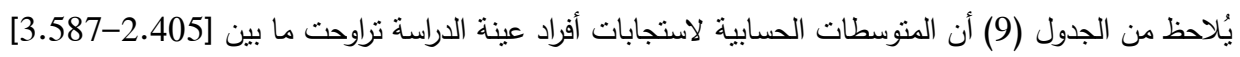

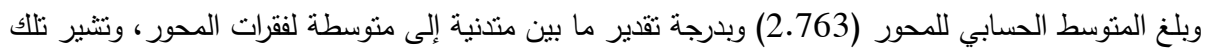

النتائج إلى ان أسلوب معاملة المرضى والمراجعين ليس بالمستوى المطلوب في المستشفيات موضوع الدراسة.

جدول (10)

مستوى خدمات الرعاية الصحية:

المتوسطات الحسابية والانحر افات المعيارية لاستجابات أفراد عينة الاراسة فيما يتعلق بمستوى خدمات الرعاية الصحية ويشير الجدول رقم (10) إلى النتائج:

\begin{tabular}{|c|c|c|c|c|}
\hline التقدير & الانحراف & المستوبط & 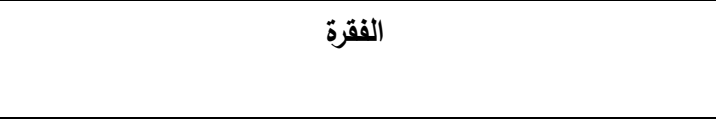 & رقم \\
\hline 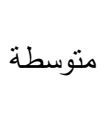 & 0.972 & 3.253 & لتشتمل الرسالة التي يتبناها المستشفى على المبادئ الاساسية & 30 \\
\hline منوسطة & 0.908 & 2.848 & تقدم المستشفى الخدمة الصحية بدرجة عالية من الدقة والموثوقية. & 31 \\
\hline متوسطة & 0.920 & 2.591 & يوجد للمسنشفى رقابة واضحة وحثينة حول الجودة. & 32 \\
\hline متننية & 1.000 & 2.769 & تتم عمليات التشخيص بدقة وكفاءة. & 33 \\
\hline
\end{tabular}


Journal of Social Sciences (COES\&RJ-JSS), 6(2), pp. 327-347

\begin{tabular}{|c|c|c|c|c|}
\hline متوسطة & 1.043 & 2.776 & تتسم الخدمة الطبية بالدقة في العلاج. & 34 \\
\hline عالية & 0.888 & 3.512 & مقارنة مع العمليات الجراحية في المستتفى بنسب عالية من النجاح & 35 \\
\hline منوسطة & 1.229 & 2.871 & الأخطاء الطبية نادرة في المستشفى. & 36 \\
\hline منوسطة & 1.152 & 2.915 & توزيع الاقسام بشكل منتظم ومريح بالنسبة للمريض. & 37 \\
\hline منوسطة & 1.195 & 2.958 & يتم انجاز الاعمال والمهام ضمن الإطار الزمني المحدد. & 38 \\
\hline 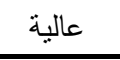 & 1.043 & 3.512 & وجود نظام زيارات مريح للمرضى والزوار . & 39 \\
\hline متوسطة & 1.261 & 3.246 & غالباً ما يشعر المريض بالرضى حول الخدمة الصحية في & 40 \\
\hline متوسطة & 1.056 & 3.023 & متوبط المحور & \\
\hline
\end{tabular}

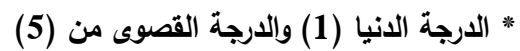

يُلاحظ من الجدول (10) أن المتوسطات الحسابية لاستجابات أفراد عينة الدراسة نراوحت ما بين [2.591-3.512] وبلغ المتوسط الحسابي للمحور (3.023) وبدرجة تقدير ما بين متوسطة وعالية لفقرات المحور ، ونتير تلك النتائج ان مستوى خدمات الرعاية الصحية ليست بالمستوى المطلوب في المستثفيات المدروسة.

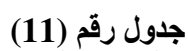

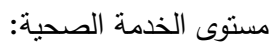

المتوسطات الحسابية لتقديرات أفراد عينة الاراسة على (11)

\begin{tabular}{|c|c|c|c|c|}
\hline الرتبة & درجة التقدير & الانحراف المعياري & المتوسط الحسابي** & 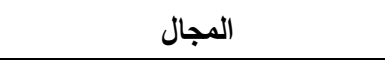 \\
\hline 1 & متدنية & 1.241 & 2.150 & فترات انتظار المرضى \\
\hline 2 & منوسطة & 1.064 & 2.763 & أسلوب معاملة المرضى والمراجعين \\
\hline 3 & متوسطة & 1.012 & 2.987 & محدودية الكادر الطبي \\
\hline 4 & متوسطة & 1.056 & 3.023 & مستوى خدمات الرعاية الصحية \\
\hline 5 & عالية & 1.156 & 3.070 & محدودية الكادر التمريضي \\
\hline 6 & منوسطة & 1.184 & 3.071 & توفر الأجهزة الطبية الحديثة \\
\hline 7 & متوسطة & 1.126 & 3.101 & توفر المستلزمات الطبية \\
\hline
\end{tabular}

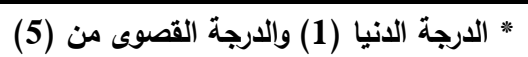

يبين الجدول (11) المتوسطات الحسابي والانحرافات المعيارية لإجابات أفراد عينة الدراسة حول محاور

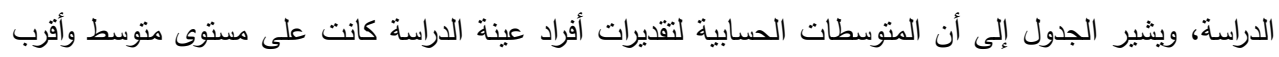

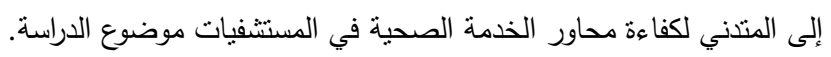
ويشير الجدول رقم (11) إلى أنفترات انتظار المرضى كانت أكبر المشكلات التي تواجهها المستشفيات الحكومية وبمتوسط حسابي بلغ (2.150)، تلاها أسلوب معاملة المرضى والمراجعين وبمنوسط حسابي بلغ (2.763) ثم محدودية الكادر الطبي وبمتوسط حسابي (2.987) تلاها مستوى خدمات الرعاية الصحية وبمتوسط حسابي 
Health Services in Governmental hospitals...

(3.023)، ثم محدودية الكادر التمريضي بمنوسط حسابي (3.070)، تلاها توفر الأجهزة الطبية الحديثة بمتوسط

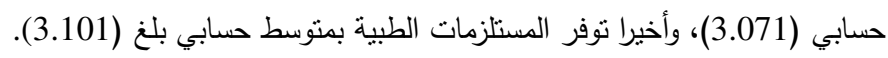

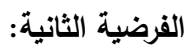

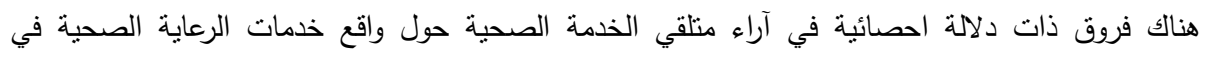

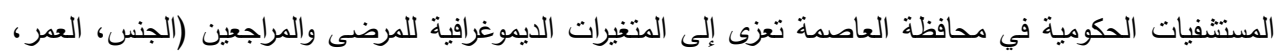

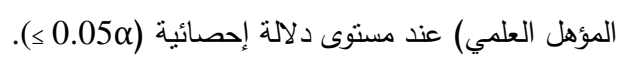

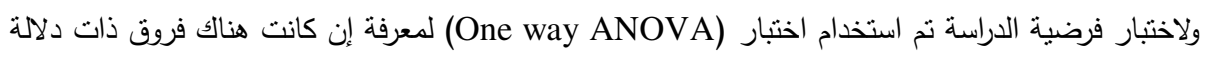

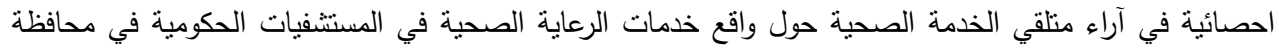

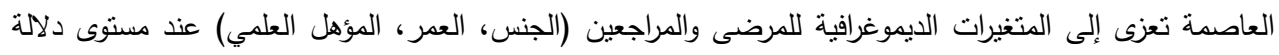

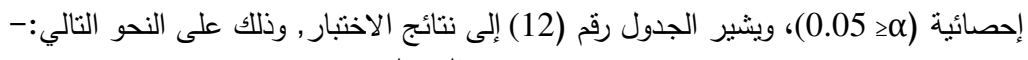

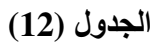

التباين الأحادي (One way ANOVA)

\begin{tabular}{|c|c|c|c|c|c|c|}
\hline مستوى الدلالة & $\mathbf{F}$ & متوسط المريعات & الحرجة & المربعات & & المتغير \\
\hline \multirow{3}{*}{0.000} & \multirow{3}{*}{66.815} & 4.218 & 19 & 80.140 & بين المربعات & \multirow{3}{*}{ الجنس } \\
\hline & & \multirow[t]{2}{*}{.063} & 662 & 41.791 & داخل المربعات & \\
\hline & & & 681 & 121.931 & المجموع & \\
\hline \multirow{3}{*}{0.000} & \multirow{3}{*}{228.643} & 73.042 & 19 & 1387.792 & بين المربعات & \multirow{3}{*}{ العمر } \\
\hline & & \multirow{2}{*}{.319} & 662 & 211.481 & داخل المربعات & \\
\hline & & & 681 & 1599.273 & المجموع & \\
\hline \multirow{3}{*}{0.000} & \multirow{3}{*}{613.464} & 103.111 & 19 & 1959.113 & بين المربعات & \multirow{3}{*}{ لمؤهل } \\
\hline & & \multirow{2}{*}{.168} & 662 & 111.269 & داخل المربعات & \\
\hline & & & 681 & 2070.383 & المجموع & \\
\hline
\end{tabular}

يثير الجدول (12) إلى وجود فروق ذات دلالة إحصائية في تقدير أفراد عينة الدراسة حول واقع خذمات الرعاية

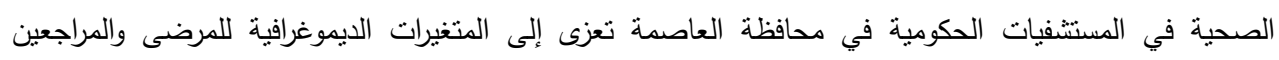

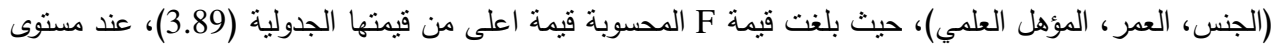

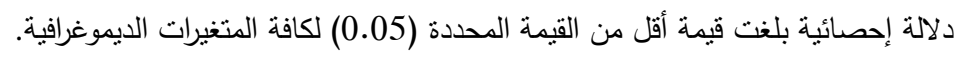

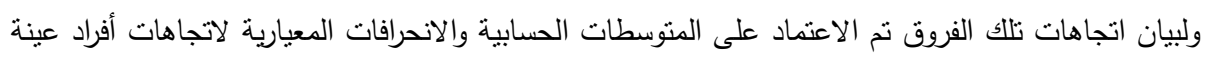

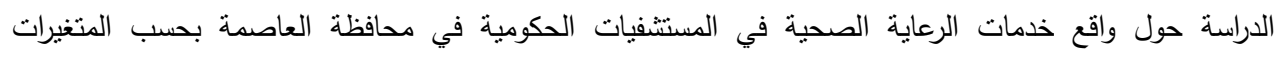
الديموغرافية والجدول رقم (13) بثير إلى النتائج: 
الجدول (13)

متوسطات تقديرات افراد عينة الدراسة واقع خدمات الرعاية الصحية في المستثفيات الحكومية في محافظة العاصمة بحسب المتغيرات الايموغر الفية الصية

\begin{tabular}{|c|c|c|}
\hline الانحراف المعياري & المتوسط الحسابي & الجنس \\
\hline .76364 & 2.9813 & ذكر \\
\hline .58905 & 3.2049 & انثى \\
\hline الانحراف المعياري & المتوسط الحسابي & العمر \\
\hline .63368 & 4.1047 & 20سنةفاقل \\
\hline .22873 & 2.8535 & 21-30سنة \\
\hline .55489 & 2.9917 & 11-31-4سنة \\
\hline .48721 & 2.6761 & 41-50سنة \\
\hline .30776 & 2.6414 & 51سنة فما فوق \\
\hline الانحراف المعياري & المتوسط الحسابي & المؤهل العلمي \\
\hline .25841 & 2.8304 & دبلوممتوسط \\
\hline .01583 & 4.1791 & بكالوريوس \\
\hline .51283 & 2.7516 & دراساتعليا \\
\hline
\end{tabular}

يشير الجدول رقم (13) إلى أن الفروق في تقدير افراد عينة الدراسة بحسب الجنس كانت لصالح الاناث

بمتوسط حسابي بلغ (3.2049)، كما كانت لصالح الأفراد ذوي العمر 20سنة فاقل بمتوسط حسابي بلغ (13) (4.1047)،

أما من حيثالمؤهل العلمي فكانت لصالح الافراد الحاصلين على شهادة بكالوريوس بمنوسط حسابي بلغ (4.1791).

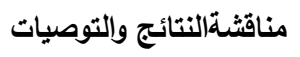

النتائج:

توصلت الدراسة إلى النتائج التالية:

1) أثنارت النتائج إلى عدم وجود مستوى عالي من الخدمة الصحية في المستشفيات المدروسة حيث أثنارت النتائج إلى

وجود مستوى يقترب من المتدني في العديد من محاور الرعاية الطبية في المسنتفيات موضوع الدراسة، وهي نتيجة توافقت مع ما توصلت اليه دراسة الضمور، وبوقجاني (2012)، والتي أثثارت الى تدني مستوى جودة الخدمات الصحية في مسنشفى الجامعة الأردنبة. 2) أشارت الدراسة إلى أن محدودية الكادر الطبي هي مشكلة تعاني منها المستشفيات المدروسة خاصة في عدم نتاسب أعداد الأطباء مع حجم المرضى في المستتفى، وأنه ليس لدى المستشفى البديل المتخصص في في حال غياب أحد الأطباء في تخصص معين. 3) كما أثنارت الدراسة إلى أن المستشفيات موضوع الدراسة تعاني من محدودية الكادر التمريضي خاصة في عدم توافر

في اعداد الممرضين على مدار الساعة، وعدم وجود عدد كافٍ من الممرضين لإتمام أعمال التمريض المطلوبة. 4) كما أشارت الدراسة إلى عدم كفاية المستلزمات الطبية حيث أنه لاتتوفر في المستشفى كافة الأدوية والمستلزمات الطبية بشكل دائم، كما يوجد نقص في مستلزمات طبية الواجب توفرها بشكل دائم. 
Health Services in Governmental hospitals...

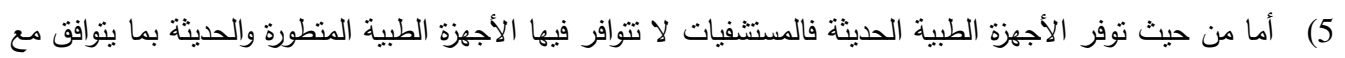

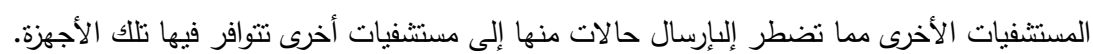

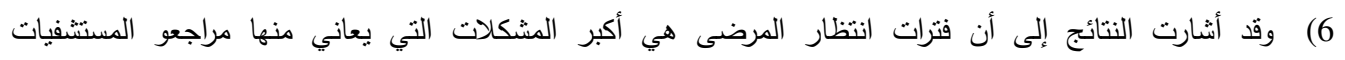

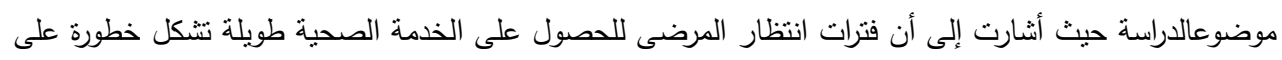

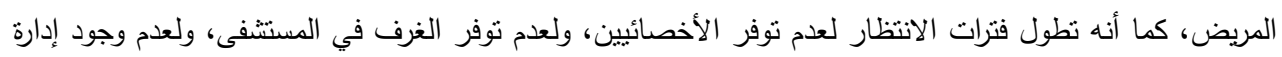

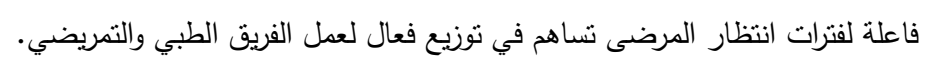

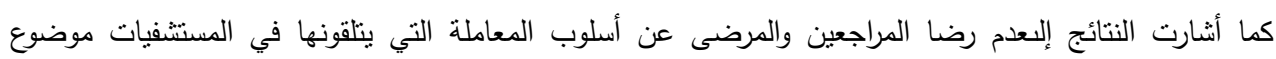

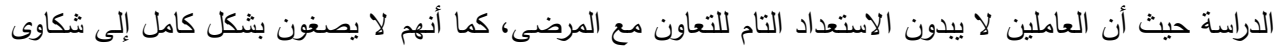

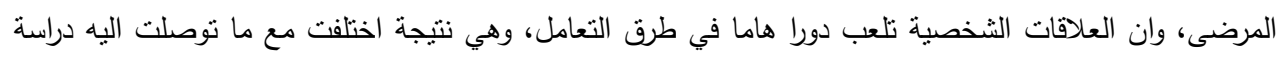

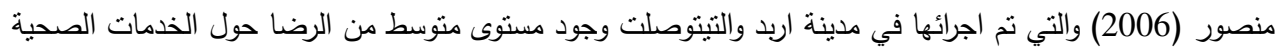
المقدمة.

8) مم أثنارت الننائج إلى ضعف مستوى الرعاية الصحية من حيث الدقة والموثوقية، وعدم وجود رقابة واضحة وحثيثة حول الجودة، وعدم الكفاءة والدقة في التثخيص، والعلاج، وفي وجود أخطاء طبية، وفي عدم توزيع الاقسام بشكل منتظم ومريح بالنسبة للمريض. 9) اثارت الننائج إلى وجود فروق ذات دلالة إحصائية في تقدير أفراد عينة الدراسة حول واقع خدمات الرعاية الصحية

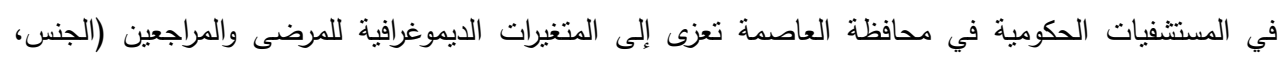

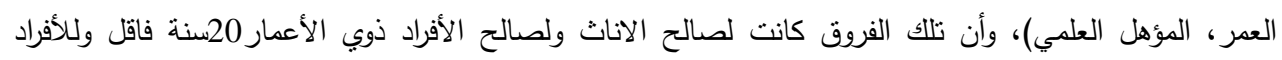

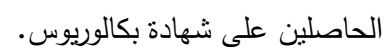

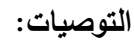

على ضوء النتائج توصلت الدراسة إلى التوصيات الثالية:

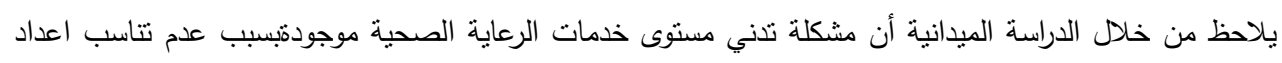

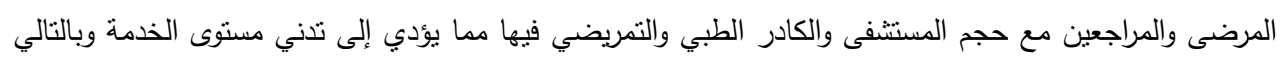

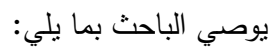
1) ضرورة العمل على زيادة مباني المستثفى وتوسيعها وتنظيمها بما يتتاسب مع حجم المرضى والمراجعين. 2) العمل على زيادة عدد الكادر الطبي والتمريضي.

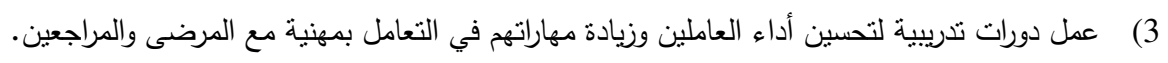

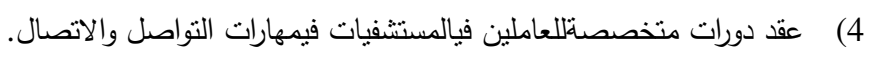

5) إلزام المستشفيات بوضع رؤية ورسالة ينم من خلالها تحقيق أهداف ترفع منمستوى الاداء فيالمستشفيات.

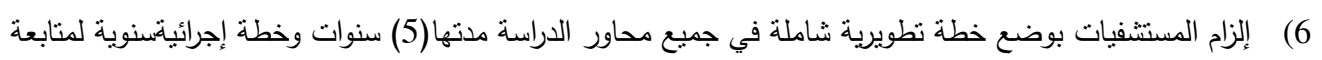

تنفيذ وإنجازات الخطة النطويرية.

7) العمل على تعميم نتائج الدراسة لما لها من أهية في تحسين مستوى الخدمة الصحية في المستشفيات الحكومية في المملكة. 


$$
\text { 8) يوصي الباحث بإجراء المزيد من الدراسات والبحوث فيما يتعلق بمسنوى الخدمة الصحية في المستشفيات الحكومية لما }
$$

\section{References}

- Abdul Qader, Mohammad. 2015, Measuring the quality of public hospital in Sudan from the perspective of patients and clients. Field study on educational hospitals in $\mathrm{Al}$ Khurtoom. Jordanian journal in business administration, 11(4).

- Abu Rmman, Asaad Hamed and Aldue jeh. 2000, "Tourism and Hospitality Marketing”, Dar Al Hamed for publishing. $1^{\text {st }}$ print Amman, Jordan.

- Al Ahmadi, Hanan Abdul Raheem, 2000. Continuous development for Quality, The concept and the implementation in health organizations, Journal of public administration, 40(3)

- Al Ahmadi, Talal bin Ayed. 2009, The evaluation of health services performance In Kingdome of Saudi Arabia. Research delivered at international conference for administration development. " Towards excellence performance in public sector, Reyad, Kingdome of Saudi Arabia Nov. 1-4

- Al Assaf, Assaf. 1994, The concept of quality in health services. University Researches foundation. Amman, Jordan.

- Al Assaf, Majd Aref, the directions of clients towards services in outpatient at public and private hospitals. Unpublished Master thesis. University of Jordan, Amman, Jordan.

- Al Dmour and Boqjani. 2012, The effect of health services quality in term of patients loyalty at university hospital - Case study. Mutah Journal for studies and research.27(3).

- Al Dustour Journal, No 23 Aug, 2015. http://www.addustour.com, Access date 10/7/2016.

- Al harrawi, Ahmad. 2016, Complains from jam in internist clinic at Al Nadim hospital. Al Dustour Journal,. July $24,2016$.

- Al Rawashdeh, Firas and Al Smadi, Ziad, 2010,"The evaluation of health services from the perspective of the health insurance beneficiaries in Jordan". Journal of business management. 6(4).

- Al Samerrai'e, Munir Jasem. 2000, The pricing of health services with focusing on dental services. High diploma in hospital management, Faculty of administration and eceonomic. Baghdad, Iraq, 11-23.

- Al shawarbeh, Imran. 2014, Spending 900 million JDs on health and complains from bad services. Al Ghad Journal, Published on 9/11/2014.

- Albakri, Thamer. 2005, Marketing of Health services, Dar Al Yazori for publishing. Amman, Jordan: 87-223.

- Bushnell , David ,S Miched B. Halus" (1992), " TQM in the public Sector: Strategies for Quality Service National productivity . Review"11(3) Summer.1992.

- Ghose, Seetesh\& Adhish, S. (2011), Patient Satisfaction With Medical Services: A Hospital-Based Study, Health and Population Perspectives and Issues.

- Kotler , Philip, and N. Clark Reporta,(2006),' Marketing for healthcare organization', Newjersy, Pentair Hall, 44-18

- Mansour, Hussein. 2006, health services delivered for inpatients at public hospitals in Irbid-Jordan. Al Manarah Journal, 13(1).

- Musleh, Ateyyah, 2009. Measuring of service quality from the perspective for employees and patients at hospitals in Qalqilyah. Open Quds university, Qalqilyah, Palestine.

- Nusairat, Farid, 2004. Management of heal care organization. Amman Jordan.

- Palmer, A., (1994),' Principles of Services marketing,, ,The McGraw - Hill co., p. (173 - 181). 
- $\quad$ Raheem, Ahmed, Nawaz, Ahmad, Fouzia, Nasir and Imamuddin, Khoso (2014), Patients' Satisfaction and Quality Health Services: An Investigation from Private Hospitals of Karachi, Pakistan, Research Journal of Recent Sciences, Vol. 3.

- Ramez, Wathek (2012), Patients' Perception of Health Care Quality, Satisfaction and Behavioral Intention: An Empirical Study in Bahrain, International Journal of Business and Social Science Vol. 3 No. 18.

Report of independent corporation for human rights. 2015.

ichr.ps/attachment/467/Report\%20on\%20Financial\%20Assistance.pdf Access date $1 / 1 / 2017$

Sekaran, U. 2003. Research Methods for Business, John Wiley and Sons.

- Sultan, Wafa', the dimensions of health services quality from the perspective of beneficiaries. Empirical study in private hospitals in Basrah. The Journal of administration and economic. Basrah, Iraq, 5(10). 